\title{
The concept of 'competence' in medical ethics
}

Elias Baumgarten Department of Humanities, The University of Michigan-Dearborn, Michigan, US $\frac{\bar{F}}{\bar{F}}$

\section{Editor's note}

Dr Baumgarten analyses three possible justifications for doctors to decide that a patient is 'incompetent' to make or participate in medical decisions affecting him, and points out the difficulties of each. He argues that the degree to which a patient relinquishes control over decision-making which affects him will vary in different circumstances and should be explicitly agreed in the initial doctor-patient contract, rather as it often is when a client employs a professional to invest money on his behalf.

\section{Introduction}

When medical patients use the term 'competence', they are generally asking about the knowledge and ability of those who are treating them. But medical ethicists find the concept of 'competence' to be even more problematic and philosophically interesting when it is applied to patients. If a patient is judged 'competent' then he is generally considered entitled to a large measure of control over medical decisions that will affect him. To exercise control requires access to relevant information, so medical staffs have a moral obligation to provide competent patients with detailed medical information on which to base their decisions. But if a patient is incompetent, then it may be not only permissible but even obligatory to make decisions for him, paternalistically to withhold information from him, and thereby to 'protect him from himself'. To clarify what is required for 'competence' in patients may be necessary for determining what kind of physician-patient relationship is morally appropriate in the treatment of different patients.

\section{Competence and the law}

Competence is a subject for the law as well as for morality, but in the law a patient is judged incompetent only in exceptional cases, in order that a significant action may be taken that opposes a person's expressed preference or when specific consent would be required and is not forthcoming. But the ethical issue extends further and seeks to determine under what conditions a physician justifiably may deny a patient the opportunity to participate in all important decisions that affect his treatment. Many recent discussions of this matter are critical of traditional paternalistic practices. ${ }^{1}$ To understand these criticisms, we must start by accepting three assumptions. First, most, if not ตैall, medical decisions include an ethical component, and physicians have no special expertise in motal decision-making. Physicians are able to provgijle information regarding the likelihood of partictur benefits and risks of treatment options, but they have no special training in determining wiat benefits are worth what risks. Unless a patient is incompetent to make ethical decisions, he shofid, therefore, at least share in the making of medical decisions that affect him. Second, a person's becoming a client (or, in the more familiar medical model, a patient) does not imply completely relinquish ing $^{2}$ the opportunity to choose among courses of treatment, unless that person should become incometent, unable to make a choice. Third, just ${ }_{-}^{-}$as individuals generally have moral obligations extend beyond what the law requires or showld require (for example, the obligation to be horest with friends), so the physician may have an ethical duty to allow competent patients to express a greater degree of autonomy than the law requiges.

Given these assumptions, the incompetint patient may yet be an exception, but there are many instances in which a physician may conside $\frac{5}{\zeta}$ it desirable to treat a patient paternalistically even though there is no question of the person's be legally incompetent. The ethical justification for such behaviour (such as the ordering of a place might be that the patient would not be competenib to make the best decision for himself on the basis. of reasonably full, truthful information. In this ethigcal sense competence implies a right to shared decisionmaking based on reasonably complete information, and the problem is to specify when the physician is and is not obliged to afford patients that opporturity.

\section{The standards for competence}

We may divide the standards proposed for competence into three kinds. The first seeks to spejify some minimal level of mental capacity that cany patient must have in order to be judged capablø్ of making or sharing in medical decisions. 'Rationality' is the most common term used in this connection. But the appeal to rationality is ambiguous. It receives its philosophical grounding in the famifiar notion that persons are essentially rational age and that it is this quality of persons that confers on us the obligation to respect their autonomy in a way that we are not obligated to respect the pie- 
ferences of other creatures. ${ }^{2}$ But in the medical context, where the emphasis is on a person's present (and often changeable) state rather than his underlying capacities, a patient's rationality is usually judged by whether he is in fact making sensible and realistic choices. This practice increases the difficulty of determining what is required for a person to be considered minimally rational.

A second kind of standard for competence disavows the attempt to establish a minimal level of functioning for all persons and instead seeks to determine whether the person in his present state is expressing preferences that are continuous with those he has expressed in the past. If the patient is judged to be acting from his 'true self', then on this standard the person is competent. The assumption is that the effects of disease and treatment often block the will of one's 'true' self (perhaps only temporarily), thus justifying or even requiring someone other than the patient to make decisions for him. The idea of a 'living will' is one institutionalised attempt to follow the patient's own true desires at a time when he cannot express them. However, this mechanism covers only life and death decisions and does not apply to the more problematic cases where a patient expresses a desire which is thought not to be his 'real' one.

A third approach to competence is to consider an understanding of medical data a necessity and thereby to argue that paternalism is justified as a general policy on the grounds that most patients lack the kind of competence that is needed to make specifically medical decisions.

Each of these approaches to defining competence poses substantial difficulties, and each sanctions a greater degree of paternalism than is considered acceptable outside the medical sphere. It will be necessary to examine each of these approaches and to see what in the medical relationship can authorise the kind of paternalistic behaviour that they appear to endorse.

To require that a patient choose rationally in order to be judged competent is to impose a heavier burden of proof for medical competence than that which we impose in other areas. Adults are not constrained from marrying unsuitable partners or wasting their money, however irrational these decisions may be. The physician who wishes to justify paternalistic behaviour simply on the grounds that a patient's choice is irrational must present morally relevant reasons why rationality should be required in order for a patient to be entitled to act autonomously, while persons in non-medical settings are not 'protected from themselves' merely because their preferences are irrational.

Several lines of thought may be advanced for distinguishing competence in patients from competence in persons outside the medical context in an attempt to justify a higher standard for competence in medical decisions. There is one difference that may influence actual practice that surely is not $\stackrel{\text { T) }}{=}$ morally relevant; namely, the fact that medical patients often do not have the physical power to ? implement their wishes. The disabling effects of a $\vec{F}$ patient's physical illness may make a person unable $\frac{\sigma}{\sigma}$ to implement his decisions and less able to resist $\frac{\square}{0}$ those of the medical staff, but these incapacities, $\overline{\bar{N}}$ whatever psychological impression they may convey $\vec{\Phi}$ of a 'weakened person', have no bearing on the $\frac{2}{0}$ patient's competence. The increased opportunity to कs be coercive creates no increased justification.

\section{Paternalistic intervention}

One might argue that something closer to rationality needs to be required in order for patients to be $\%$ allowed to exercise autonomy, even though it is not required of others, because medical decisions are $\%$ more significant; more is at stake. But this is not 0 always the case. A person's decision not to seek medical help for a serious illness may be both irrational and life-threatening, yet such a person ${ }_{\odot}^{\infty}$ would be unlikely to be considered incompetent, $a \frac{\mathbb{}}{3}$ candidate for paternalistic intervention. A person's fear of cancer may irrationally delay his visit to a physician until effective treatment is no longer $\vec{\theta}$

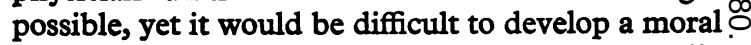
case for going beyond efforts at persuasion actually to coerce him to seek treatment or even, were it possible, to deceive him into being diagnosed without his knowledge.

A stronger case for paternalism within a medical $\stackrel{\circ}{\circ}$ setting seems to be based on the contract a person $\stackrel{\vec{F}}{\vec{F}}$ makes with a physician when he does in fact come $\frac{3}{3}$ for treatment. By becoming a patient, a person may be said to make an implicit agreement to allow the physician to take the steps he judges to be medically necessary. By 'coming under a doctor's care', accepting doctor's orders, a patient consents to be in: a different kind of relationship with a physician than 3 . he might be with a stranger who would seek to 'protect him against himself' (by, for example, withholding relevant information from him). This iso certainly true, but significant questions remain: How different? Different in what respects? Phraseso such as 'under a doctor's care' are descriptive of the way in which the physician-patient relationship haso been conceived in the past, but they are not neces- $N$ sarily sound prescriptions for the future. Nor, on N the other hand, should it be assumed that all elements of paternalism in the relationship are morally inappropriate. But if the justification for paternalism derives partly from a kind of contract ao patient enters into with a physician, then we must look more closely at the nature of that agreement.

\section{The competent patient}

Let us limit ourselves to the case of an adult who himself decides to seek medical help. This is theo 
most usual case, and much of the discussion could be applied, with modifications, to other situations as well. Two points should be noted at the outset. First, the agreement is morally binding only if both parties are judged competent to choose to enter into it in the first place. Second, if anything is clear about the nature of the agreement, it is, paradoxically, its vagueness. In it the patient neither gives nor explicitly denies consent for the physician to impose treatment, to mislead, or to withhold information for what he judges to be the benefit of the patient. In practice the terms of the contract depend in large measure on the interpretations that physicians wish to give them.

The fact that a patient is competent when he enters into an agreement does not imply, of course, that he must be judged competent thereafter. One might argue that he 'puts himself in the hands of the physician' precisely because he recognises that illness can make him choose irrationally. There is, therefore, no logical contradiction in saying that a competent person enters into an agreement to allow another person, at a later date, to consider him incompetent and to act against his irrational wishes 'for his own good'. (The agreement presumably would indicate whether and how this permission may be revoked.) There is nonetheless a practical danger of requiring 'rationality' for medical competence. The danger is that any time a patient expresses what the physician judges to be an irrational preference, the patient himself will be judged to be irrational, hence incompetent and requiring paternalistic intervention. No such judgment is likely to be made outside the medical context because we recognise that even a competent person with the capacity for rational judgment might make individual decisions that we find irrational. Within a medical setting even one seemingly irrational choice is temptingly identifiable with 'loss of rational capacities' for at least two reasons. First, physicians probably have insufficient experience with each patient to judge his general capacities beyond the particular medical choices he makes. Second, however rational a person may have been generally, a single irrational choice may be regarded as evidence of incompetence, a loss of rationality, owing to the effects of the disease (or treatment) itself. Outside the medical context there is no such easily identifiable cause of disablement that would allow us to regard a formerly competent person as needing protection from himself, however unwise his particular choices may appear to be.

There is no question that some patients lack rational capacities and perhaps have a right to paternalistic protection; many of these will be legally incompetent. But there are many others whose preferences may appear irrational who nonetheless must be considered ethically competent; that is, entitled to share in medical decisions, just as they would be entitled to make other significant decisions in their lives. If the original agreement $\frac{\text { TI }}{F}$ between competent person and physician is to be the basis for subsequently treating the patient as. incompetent, then that agreement will need to be $\overrightarrow{\vec{F}}$ spelled out in considerably greater detail than is thecurrent practice. I will have more to say about this등 later.

If a patient does not, in coming to a physician,,$\widehat{\mathbb{D}}$ explicitly consent to relinquish control over decision-making, then there is no justification for ${ }^{\infty}$ overriding a patient's wishes simply because they $\vec{O}$ express values that may appear irrational to the $\vec{\overrightarrow{ }}$ physician. But paternalism is argued for not only on ${ }_{\sigma}$ the grounds that the patient's immediately expressed wishes are not rational, not truly in his own best $\Phi$ interests, but also on the grounds that they are not. the patient's own real wishes. Here the physician: recognises an obligation to respect the patient's ${ }^{\circ}$ genuine choices but claims that because of illness음 and treatment, the patient's 'true self' is no longerable to express itself. It is the will of that true selfthe person's former self and, it is hoped, future selfo -that the physician feels obligated to respect; $\stackrel{\mathbb{D}}{3}$ accordingly, a physician might justify overruling a person's current preferences or, more usually, withholding information that would lead to their ${ }_{\infty}$ expression.

There are at least two problems with this justification, one pertaining to the effects of the illness, the other to our conception of the medical contract.o First, it assumes that illness always distorts aڤ person's true wishes, when in fact it may at times $\stackrel{\square}{\circ}$ realistically shape them. Sickness may be a trans- $\overrightarrow{\vec{P}}$ forming experience in a person's life, and a radically 3 changed will that results from it may be as much an? expression of the person's true self as the changes in? desire that may result from such events as childrearing, loss of a loved one, or a spiritual conversion. Such experiences challenge the notion that the 'real' desires of a 'true' self are constant throughout a lifetime; to assume that they are may represent a covert claim that one's real will, embedded beneath the 'distortions' of everyday hopes and fears, is a 9 purely rational will. But if we are seriously to respect $>$ the autonomy of a diversity of individual wills (often based on hopes and fears), then a person cannot be $\bar{N}$ judged incompetent merely because his desires after the onset of an illness are different from what they $N$ were before.

If we must confess ignorance as to whether discontinuity in a person's will reflects incompetence, 0 then the justification for supposing an expressed $\mathbb{D}$ desire to be contrary to a patient's true self cannot? be based solely on the physician's judgment but $T$ must rest upon a prior explicit agreement between $\stackrel{\vec{D}}{\vec{D}}$ patient and physician. A person may freely enter $\stackrel{?}{\stackrel{P}{0}}$ into a contract that binds his future will, both in $\stackrel{\mathbb{Q}}{\unrhd}$ medical and non-medical areas. A patient would be $\overline{0}$ wise to delegate control to his physician with great $ᄋ$ care, and one could err tragically in either direction. 
In practice the development of such a contract might become as routine a part of establishing a medical relationship as a diagnostic interview or the gathering of medical insurance data. A physician would be given general guidelines, which he could at the outset accept or reject, both about the patient's wishes and the extent to which he consents to have the physician substitute his own judgment for the patient's. In this way the physician would at least have some grounds for asserting knowledge of a patient's 'true' desires, and while a patient might improperly choose to impose his present desires on a future self, that is still ethically more defensible than a physician's imposing his idea of the patient's true desires on that self. And since a patient always retains the right to discontinue the contract for treatment by a physician, he would also be able to renegotiate the original contract.

But, it will be argued, medical decisions are too diverse, too sensitive, too complicated to be reduced to contractural formulas. Persons may be able to retain decision-making power when they are clients of a stockbroker or a lawyer, but very few persons are capable of understanding medical information and coming to appropriate decisions based on it. If this argument is to justify paternalism, it must add, moreover, that most persons are not aware of their ignorance and would contract for more authority than would be good for them.

The last claim is factually questionable. There is every reason to believe that many persons, given the choice, would prefer not to be involved in medical decisions. ${ }^{3}$ To claim, however, that most people are unable to make this choice amounts to an assertion that virtually all persons are incompetent with regard to medical matters. And this may be, implicitly, the most usual justification for paternalism of all: it is neither irrationality nor discontinuity with a true self that renders the average patient incompetent; rather, it is the complexity of medical decisions in relation to the lay person's ability to deal with them that disqualifies him.

To support this claim, one would need to show that the ethical dimension in medical decisions cannot be isolated from the wealth of factual, technical data, that the latter are beyond the patient's comprehension, and that there is no way of summarising the relevant medical facts in a manner that will permit the patient to express an ethical choice; for example, a judgment that the risks of disability as the physician has outlined them are not worth the indicated likelihood of benefits.

Even if all these claims were true, the conclusion that patients are incompetent to make all medical decisions would still be problematic. Most patients are expected to make one ongoing medical decision; namely, to continue or to terminate their contract with a physician. If patients are judged to be totally incapable of evaluating the care they receive as a consequence of being unable to understand it, then they can hardly be competent to judge whether to continue treatment. This would imply that a patient can have no legitimate grounds for terminating a medical contract or for replacing the services of one physician with another - except, perhaps, on the basis of a personality clash. Since even those who argue for paternalism do not conceive the contract of patient and physician in such absolute terms, their argument for the medical incompetence of the average patient is internally inconsistent. " If patients were truly incompetent to evaluate and share in medical decisions, then they would have no legitimate grounds for ever terminating their relationship with a physician.

\section{Conclusion}

Finally, the issue of competence extends beyond the personal relationship of a physician to his patient and raises a more general social question about the medical establishment's conception of the capabilities of potential as well as actual patients. Even given the strongest case for the incapacity of untrained persons to make medical decisions, the potential patient might be regarded as in a similar position with respect to medical decisions as the mildly retarded are in relation to everyday decisions, or as the person of normal intelligence would be in a society for the gifted. ${ }^{5}$ Such a person still would be entitled to act autonomously and would be competent to judge for himself what his own limitations are.

He would, therefore, seek out guidance from a friendly gifted person; or if he did not, he would at least be in a position to assess the risks attendant on making his own decisions. While, by hypothesis, he is incompetent to make many kinds of decisions that society requires of him, he remains fully competent to recognise his limitations and to decide to seek help. ${ }^{\circ}$

The obligation of the gifted, of those with specialised knowledge in medicine as in other professions, is to make sufficient information generally available to permit the average person to make an informed choice whether to seek help, and in what form. After the person has sought help, the professional is obliged to continue to provide sufficient information so that his client may decide whether or not to continue the original relationship. The degree to which a person, in becoming a medical patient, relinquishes a claim to complete information and decisionmaking power should be agreed upon in the original contract, just as it is when a person freely invests his money for handling by a professional. When the importance of specified agreements between physicians and patients becomes more generally recognised and discussed in the society at large, it will also be evident that no absolutely clear limits can be set in advance. That argues for generality, for caution, for periodic reassessment, and for mutual 
trust. It does not argue for the present system in which the understood terms of each agreement can vary only from physician to physician, but not from patient to patient.

\section{Notes and references}

'Buchanan, A (1978). Medical paternalism. Philosophy and public affairs. 7/4, 370-390.

${ }^{2}$ The most notable expression of this view is found in Kant, Immanuel (1949). Fundamental principles of the metaphysic of morals. Indianapolis, Library of Liberal Arts, pp 45ff.
A majority of patients who were given the option chose not to be informed of the risks of various proced in a recent study. See Alfidi, $\mathrm{R}$ J (1975). Controvefsy, alternatives and decisions in complying with the legal doctrine of informed consent. Radiology, $f_{4}$, I; 23I-234. Reprinted in Contemporary issue in bioethics, Beauchamp, T L and Walters, L (eds) (1978). Encino, California, Dickenson Publiskifing Company Inc. pp I46-150.

'Buchanan, op cit, pp 383-385.

${ }^{5}$ Wikler, D (1979). Paternalism and the mildly retarded. Philosophy and public affairs, 8/4, 377-392.

'Ibid, p 389. 